Products and Services In Practice is provided to readers using text and images from the manufacturer, supplier or distributor and does not imply endorsement by $B D J$ In Practice. Normal and prudent research should be exercised before purchase or use of any product mentioned.

Please send product and services news through to David Westgarth, BDJ In Practice via: David.Westgarth@bda.org

\section{Made for the modern practice}

Eschmann remains at the cutting-edge of infection control with the release of its new Little Sister SES 3020B autoclave.

Featuring a larger 23-litre capacity, the system is able to process up to $6 \mathrm{~kg}$ of instruments as well as instruments up to $370 \mathrm{~mm}$ in length using a dedicated long instrument tray. Despite this impressive capacity, the system can still comfortably fit on standard sized work surfaces, making it a compact and efficient option.

The Little Sister SES 3020B also offers professionals a choice between 'B' type vacuum or ' $\mathrm{N}$ ' type non-vacuum cycles. These cycles have selectable drying that is automatically optimised to the weight of the instrument load so that every cycle is tailored to your needs.

Plus, the Little Sister SES 3020B has a number of additional features such as dedicated handpiece cycles, daily and weekly test cycles and specific sterilisation and drying cycles for implant kit processing.

For more information on the highly effective and affordable range of decontamination equipment and products from Eschmann, visit www. eschmann.co.uk or call 01903875787.

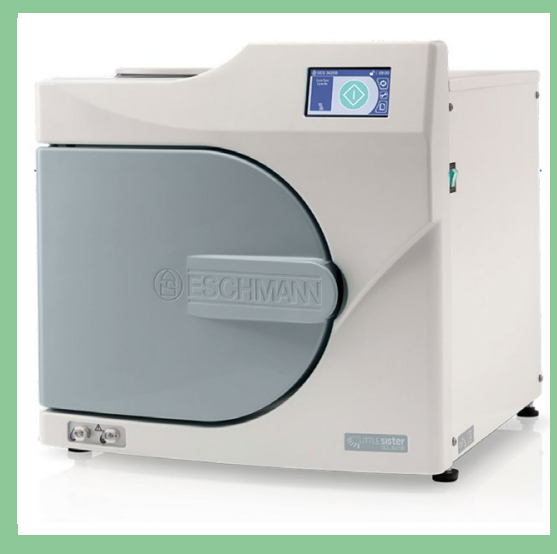

\section{New brushhead launched}

Philips newly launched premium, multifacted brushhead is designed to brush away plaque, remove stains and care for gums in ways not possible with a manual toothbrush. The angled bristles of the Allin-One brushhead help remove up to 20 times more plaque, whilst providing flex to compensate for any excess pressure exerted by the brusher.

The triangular tips can remove up to $100 \%$ more stains in less than two days and the longer bristles provide a deep clean for gums, which as a result, ensures the gingiva is up to 15 times healthier.

The new All-in-One brushhead has been designed to provide complete care, helping Sonicare users to achieve cleaner, whiter teeth and healthier gums more effectively.
Happily the brushhead fits every Sonicare toothbrush, so patients can upgrade their brushing efficiency without changing their brush.

A brushead dual pack is available for sale in dental practices for $£ 9.99$ and has a recommended retail price of $£ 29.99$. For more information contact dental.sales. support@philips.com.

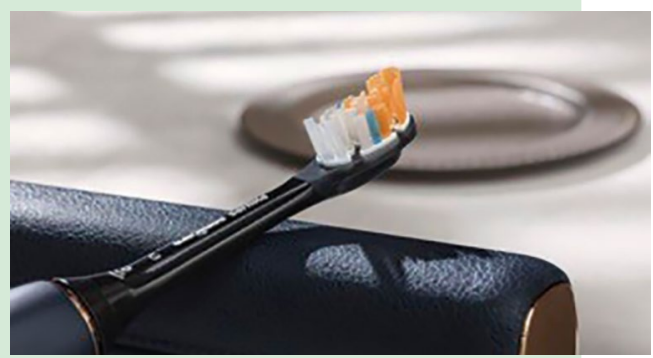

\section{Discover YOUR Handpiece}

Coming from W\&H, you already know that the speed-increasing Synea Fusion dental turbine handpiece is going to offer exceptional features and value.

Do you want strong torque, but also comfort and control at the same time? The Synea Fusion dental turbine fuses power and excellent ergonomics to ensure smooth handling.

Do you want to work faster with less downtime? The Synea Fusion has also been designed for minimal maintenance while maximising hygiene, particularly as it is optimised to ensure minimal aerosol production. Quick and easy bur changes allow you to work more efficiently without hassle.

There's so much more to say about this instrument.

To Find out why the Synea Fusion dental turbine is YOUR handpiece visit www. wh.com/en_uk, call 01727874990 or email office.uk@wh.com.

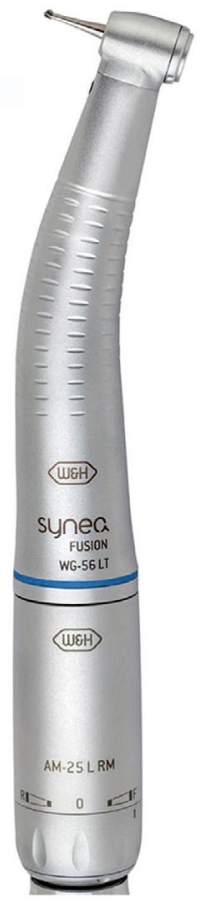

